\title{
Spatially distinct roles of class Ia PİK isoforms in the development and maintenance of PTEN hamartoma tumor syndrome
}

\author{
Qi Wang, ${ }^{1,2}$ Thanh Von, ${ }^{1,2}$ Roderick Bronson, ${ }^{3}$ Minzi Ruan, ${ }^{4}$ Wenxia Mu, ${ }^{4}$ Alan Huang, ${ }^{5}$ \\ Sauveur-Michel Maira, ${ }^{6}$ and Jean J. Zhao ${ }^{1,2,7}$ \\ ${ }^{1}$ Department of Cancer Biology, Dana-Farber Cancer Institute, Boston, Massachusetts 02215, USA; ${ }^{2}$ Department of Biological \\ Chemistry and Molecular Pharmacology, Harvard Medical School, Boston, Massachusetts 02215, USA; ${ }^{3}$ Dana-Farber/Harvard \\ Cancer Center Rodent Histopathology Core, Harvard Medical School, Boston, Massachusetts 02215, USA; ${ }^{4}$ VigeneTech, Inc., \\ Carlisle, Massachusetts 01741, USA; ${ }^{5}$ Novartis Institutes for Biomedical Research, Cambridge, Massachusetts 02139, USA; \\ ${ }^{6}$ Novartis Institutes for Biomedical Research, Ch4002 Basel, Switzerland
}

PTEN hamartoma tumor syndrome (PHTS) comprises a collection of genetic disorders associated with germline mutations in the tumor suppressor gene PTEN. Therapeutic options and preventative measures for PHTS are limited. Using both genetically engineered mouse models and pharmacological PI3K isoform-selective inhibitors, we found that the roles of PI3K isoforms are spatially distinct in the skin: While p110 $\alpha$ is responsible for the sustained survival of suprabasal cells of the epidermis in the absence of PTEN, p110 $\beta$ is important for the hyperproliferation of basal cells in PHTS. Furthermore, we identified a differential expression pattern of $p 110 \alpha$ and $p 110 \beta$ in basal and suprabasal keratinocytes as well as differential PI3K regulation by upstream signals in the basal and suprabasal compartments of the epidermis, providing a potential molecular mechanism underlying the specific roles of PI3K isoforms in the epidermis. Finally, we demonstrate that combined inhibition of both PI3K isoforms prevents the development of PHTS and also reverses skin hamartomas that have reached advanced stages in mice. Together, these results not only advance our overall understanding of the diverse roles of PI3K isoforms, but also have the potential for meaningful translation via the clinical utilization of PI3K inhibitors for both prevention and therapy in PHTS patients.

[Keywords: genetic mouse models; PI3K inhibitors; PI3K isoforms; skin; PTEN hamartoma tumor syndrome] Supplemental material is available for this article.

Received February 14, 2013; revised version accepted June 14, 2013.

While somatic loss of PTEN tumor suppressor function is a frequent event in various sporadic human cancers (Sulis and Parsons 2003; Salmena et al. 2008), germline mutations in the PTEN gene cause several genetic or congenital disorders, including Cowden syndrome (CS), BannayanRuvalcaba-Riley syndrome (BRRS), Proteus syndrome (PS) and Proteus-like syndrome (PLS), all characterized by multiple hamartomas occurring over various areas of the body. Collectively, these disorders are termed PTEN hamartoma tumor syndromes (PHTSs) (Blumenthal and Dennis 2008; Hobert and Eng 2009). CS, the prototypic syndrome, is characterized by a variety of skin lesions, which include papillomatous papules and acral and plantar keratosis, and is also associated with increased suscepti-

${ }^{7}$ Corresponding author

E-mail jean_zhao@dfci.harvard.edu

Article is online at http://www.genesdev.org/cgi/doi/10.1101/gad.216069.113. bility to breast, thyroid, and endometrial cancers (Liaw et al. 1997; Gustafson et al. 2007; Blumenthal and Dennis 2008; Hobert and Eng 2009). Notably, the occurrence of multiple skin hamartomas is the most common clinical manifestation of PHTS and occurs in almost all patients with CS (Hobert and Eng 2009), suggesting that PTEN/ PI3K play important roles in the maintenance of skin epidermal homeostasis, as demonstrated by previous studies (Backman et al. 2004; Cully et al. 2006; Pankow et al. 2006).

PTEN is a lipid phosphatase that dephosphorylates the 3'-phosphoinositide products of the class Ia PI3Ks in epithelial cells by converting phosphatidylinositol $(3,4,5)$ trisphosphate (PIP3) to phosphatidylinositol $(4,5)$ bisphosphate (PIP2), thus counteracting class Ia PI3K activity. A reduction in 3'-phosphoinositides decreases the activity of kinases downstream from class Ia PI3Ks, such as Akt, and $\mathrm{mTOR}$, and is responsible for much if not all of the 
tumor suppressor activity of PTEN (Sulis and Parsons 2003; Cully et al. 2006; Salmena et al. 2008). The class Ia PI3K family contains three highly homologous p110 catalytic isoforms $(\mathrm{p} 110 \alpha, \mathrm{p} 110 \beta$, and $\mathrm{p} 110 \delta)$ encoded by three distinct genes: Pik3ca, Pik3cb, and Pik3cd, respectively. In mammals, the expression of p1108 is largely restricted to the immune system, while p110 $\alpha$ and $\mathrm{p} 110 \beta$ are expressed in all epithelial tissues and organs (Vivanco and Sawyers 2002; Liu et al. 2009). Recent studies have demonstrated that $\mathrm{p} 110 \alpha$ and $\mathrm{p} 110 \beta$ play distinct roles in both signaling and cellular transformation (Jia et al. 2009; Vogt et al. 2009; Vanhaesebroeck et al. 2010). While p $110 \alpha$ is the major effector downstream from receptor tyrosine kinases (RTKs) (Zhao et al. 2006; Graupera et al. 2008; Utermark et al. 2012), p110 $\beta$ is obligatory for signaling via G-protein-coupled receptors (GPCRs) and for RTK signaling in certain limited circumstances (Graupera et al. 2008; Guillermet-Guibert et al. 2008; Jia et al. 2008; Ciraolo et al. 2010). We previously reported that ablation of $p 110 \beta$, but not $p 110 \alpha$, is sufficient to inhibit prostate intraepithelial neoplasia (PIN) induced by Pten loss in a mouse prostate tumor model (Jia et al. 2008). A recent study by Vanhaesebroeck's group (Berenjeno et al. 2012) using knock-in mouse models of kinase-dead alleles of $p 110 \alpha$ or $p 110 \beta$ shows that, while, indeed, inactivation of $p 110 \beta$ but not $p 110 \alpha$ blocks prostate tumor development, both $p 110 \alpha$ and $p 110 \beta$ isoforms can modulate the impact of Pten loss in other tissues. Thus, identification of which p110 isoform is responsible for the transformation induced by Pten loss in any given tissue or tumor type remains intriguing as well as challenging.

\section{Results}

Genetic ablation of both $p 110 \alpha$ and $p 110 \beta$ isoforms of PI3K completely blocks the development of multiple skin hamartomas induced by Pten loss

We set out to identify the specific roles of the $p 110 \alpha$ and $p 110 \beta$ isoforms of class Ia PI3K in a murine model of CS. We first crossed mice carrying a floxed Pten allele with mice carrying a K14Cre transgene, as described in a previously reported mouse model of CS (Squarize et al. 2008). Over time, these mice developed multiple dermal lesions closely resembling skin PHTS. We then generated cohorts of compound mice with K14Cre, K14Cre; Pten $^{L / L}$, K14Cre;Pten ${ }^{L / L} ; p 110 \alpha^{L / L}$, K14Cre $;$ Pten $^{L / L} ; p 110 \beta^{L / L}$, and K14Cre;Pten ${ }^{L / L} ; p 110 \alpha^{L / L}{ }_{;}^{\prime} p 110 \beta^{L / L}$ genotypes (hereafter termed wild-type, Pten ${ }^{\Delta}$, Pten $^{\Delta} ; p 110 \alpha^{\Delta}$, Pten $^{\Delta} ; p 110 \beta^{\Delta}$, and $P$ ten ${ }^{\Delta} ; p 110 \alpha^{\Delta} ; p 110 \beta^{\Delta}$ mice) to facilitate concurrent ablation of Pten with either $p 110 \alpha$ or $p 110 \beta$ in epidermal keratinocytes. These mice were viable and appeared normal from birth up to $3 \mathrm{wk}$ of age. The Pten ${ }^{\Delta}$ mice developed skin lesions progressively after weaning and, within 12 wk, presented with multiple cutaneous hamartomas found all over the body. The most visible symptoms were papillomatous lesions around the facial orifices, ears, and paws, and most of these were associated with hyperkeratosis (Fig. 1A; Supplemental Fig. 1A). The progression of skin hamartoma in Pten $^{\Delta}$ mice was eval-

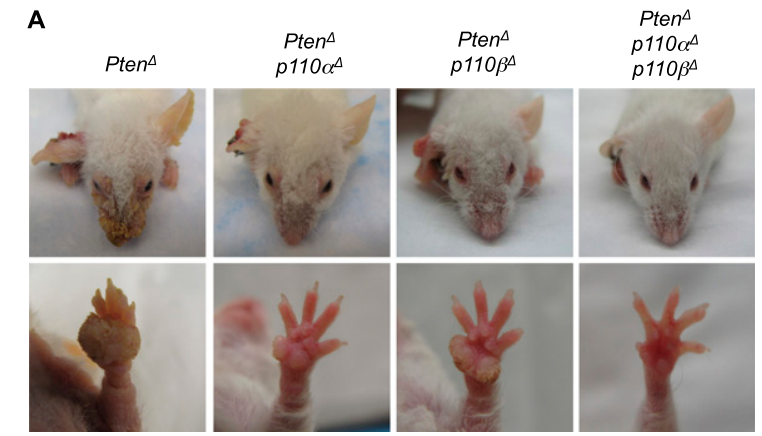

B

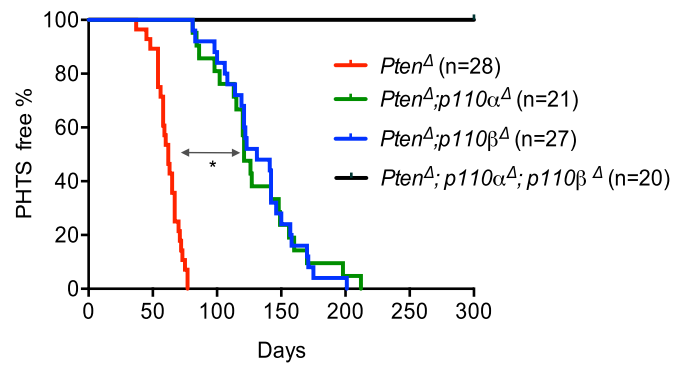

Figure 1. Effects of genetic ablation of $p 110 \alpha$ and/or $p 110 \beta$ on the development of PHTS in mice. $(A)$ Representative photos of the heads and left front paws of mice of the indicated genotypes at 12 wk of age. $(\Delta)$ Deletion status of the floxed alleles. $(B)$ Kaplan-Meier (KM) curves showing the onset of PHTS in mice of the indicated genotypes. The median skin hamartoma onset for ten $^{\Delta}$ mice (red line) is $62 \mathrm{~d}$. Ablation of either $p 110 \alpha$ (green line) or $p 110 \beta$ (blue line) delayed symptom onset to 121 and $131 \mathrm{~d}$, respectively. $\left(^{\star}\right) P<0.001$ (log-rank test). All $P t^{*} n^{\Delta} ; p 110 \alpha^{\Delta} ; p 110 \beta^{\Delta}$ mice remained free of PHTS symptoms for at least $300 \mathrm{~d}$ (black line).

uated according to the pathological criteria of PHTS as described in previous studies (Supplemental Fig. 1B; Nelen et al. 1996; Eng 2000; Laury et al. 2011). The median onset of disease in Pten ${ }^{\Delta}$ mice was $62 \mathrm{~d}$ (Fig. 1B, red line). There were no significant differences in the severity and time to onset of these skin lesions comparing male and female Pten ${ }^{\Delta}$ mice (Supplemental Fig. 2). Although ablation of either the $p 110 \alpha$ or $p 110 \beta$ gene significantly delayed the development and severity of the skin lesions induced by Pten loss in keratinocytes (Fig. 1; Supplemental Fig. 1B), all Pten ${ }^{\Delta} ; p 110 \alpha^{\Delta}$ and Pten $^{\Delta} ; p 110 \beta^{\Delta}$ mice developed skin hamartomas with a median latency of 121 and $131 \mathrm{~d}$, respectively (Fig. 1B). Remarkably, however, Pten $^{\Delta} ; p 110 \alpha^{\Delta} ; p 110 \beta^{\Delta}$ mice, in which both $p 110 \alpha$ and $p 110 \beta$ isoforms were ablated, did not develop hamartomas over an observation period of $300 \mathrm{~d}$ (Fig. 1). This finding suggests that both $\mathrm{p} 110 \alpha$ and $\mathrm{p} 110 \beta$ are essential to the development of skin lesions in the absence of Pten.

Loss of both $p 110 \alpha$ and $p 110 \beta$ isoforms of PI3K is required to counteract Pten loss-induced hyperphosphorylation of Akt and restore the normal skin thickness and architecture in the absence of Pten

To examine the effect of the PI3K/Pten pathway activation on the epidermis of adult mice, we carried out 
Wang et al.

histological analyses on skin biopsies from adult mice with various $\mathrm{PI} 3 \mathrm{~K} /$ Pten genotypes at $8 \mathrm{wk}$ of age, prior to the formation of hamartomas. Pten ${ }^{\Delta}$ mice showed significantly thickened skin with a marked increase in the number of epidermal cell layers (Fig. 2A). Keratinocytespecific Pten-null mice with concomitant ablation of either PI3K isoform (Pten ${ }^{\Delta} ; p 110 \alpha^{\Delta}$ or Pten ${ }^{\Delta} ; p 110 \beta^{\Delta}$ mice) did not display increased skin thickness to the same degree as the Pten $^{\Delta}$ mice, but their epidermal layers were still significantly thicker than those of wild-type control mice (Fig. 2A). Notably, in Pten-deficient epidermis, concurrent ablation of both PI3K isoforms $\left(\right.$ Pten $\left.^{\Delta} ; p 110 \alpha^{\Delta} ; p 110 \beta^{\Delta}\right)$ restored epidermal thickness and skin architecture to a normal state (Fig. 2A). Consistent with this, Western blot analyses of epidermal samples isolated from mice with these genotypes demonstrated that the increased levels of Akt phosphorylation observed in the absence of Pten were partially reduced by ablation of either $p 110 \alpha$ or $p 110 \beta$ (Fig. 2B). Only concurrent deletion of both $p 110 \alpha$ and $p 110 \beta$ reduced the elevated Akt phosphory-
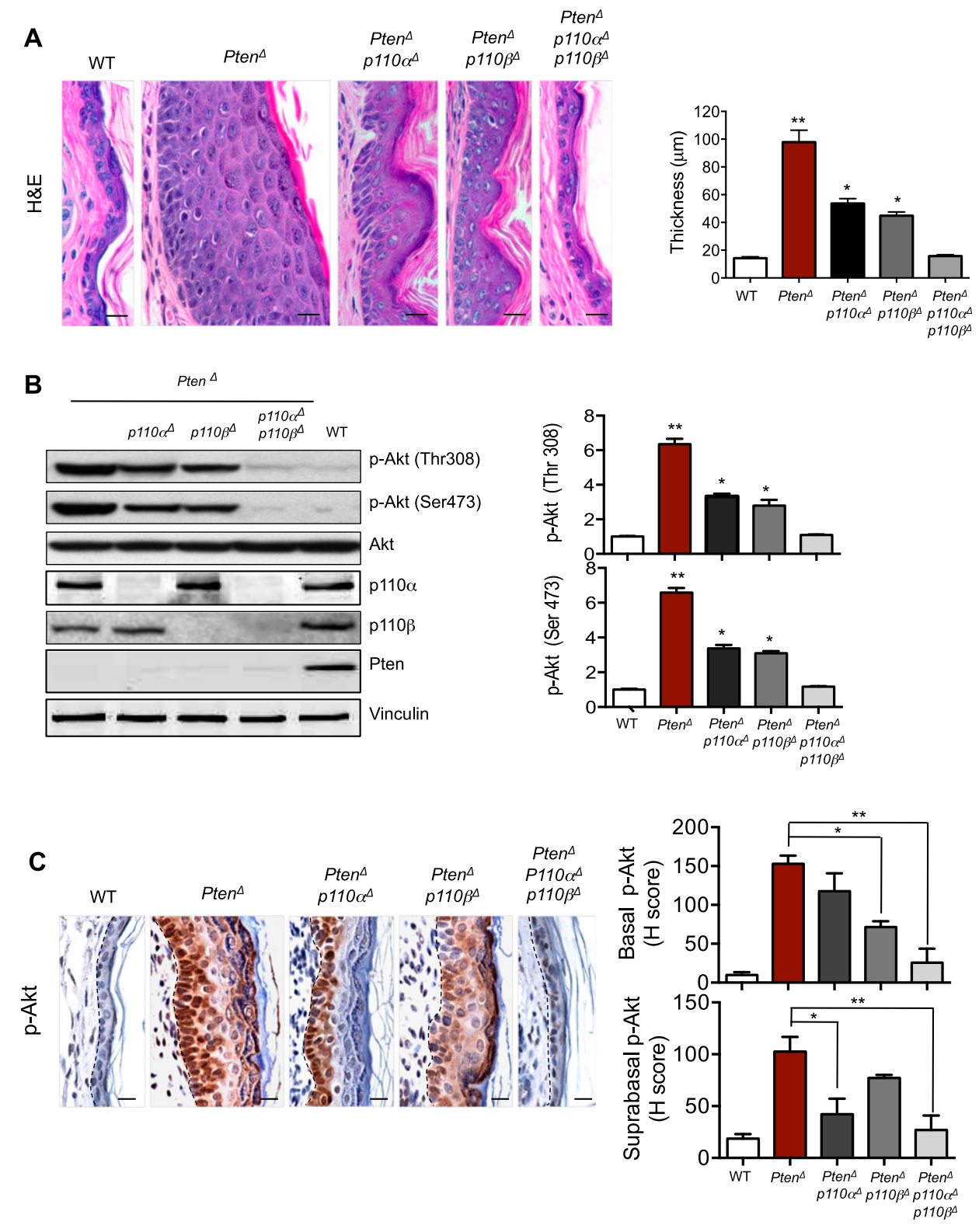

Figure 2. Effects of $p 110 \alpha$ and/or $p 110 \beta$ ablation on skin epidermis in the absence of Pten. (A) hematoxylin and eosin (H\&E) staining of skin sections from ears of 8 -wk-old mice of the indicated genotypes. Bar, $20 \mu \mathrm{m}$. The bar graph represents the thickness of the epidermis from mouse ears of the indicated genotypes. Data are shown as mean $\pm \operatorname{SEM}\left(n=6\right.$ for each genotype). $\left(^{\star}\right) P<^{*} 0.01 ;\left(^{\star \star}\right) P<$ 0.001 (Student's $t$-test). $(B)$ Western blot analyses of p-Akt in primary keratinocytes isolated from mice of the indicated genotypes. Data are shown as mean $\pm \operatorname{SEM}(n=6) .\left(^{\star}\right) P<0.01 ;\left(^{\star \star}\right) P<0.001$ (Student's $t$-test). $(C)$ IHC analyses of p-Akt in epidermal sections of ears from 8-wk-old mice of the indicated genotypes. Dashed lines mark the epidermal-dermal junction. Bar, $20 \mu \mathrm{m}$. Histogram scores (H-scores) of p-Akt in basal and suprabasal epidermis are shown as mean \pm SEM $(n=6) .\left(^{\star}\right) P<0.01 ;\left(^{\star \star}\right) P<0.001$ (Student's $t$-test). 
lation levels induced by Pten loss to normal levels (Fig. 2B).

Immunohistochemistry (IHC) analysis of phospho-Akt (p-Akt) revealed compartmentalization differences not detectable in Western blotting: While cytoplasmic p-Akt levels were increased in cells in all layers of the thickened Pten-null skin, surprisingly, we found nuclear p-Akt staining in cells in the inner layers of the epidermis, forming two zones of p-Akt staining (Fig. 2C; Supplemental Fig. 3). More interestingly, while ablation of $p 110 \alpha$ markedly reduced the cytoplasmic p-Akt signal in the outer layer cells of the Pten-null skin, ablation of $p 110 \beta$ greatly diminished nuclear p-Akt in the inner layer cells of Ptennull skin (Fig. 2C; Supplemental Fig. 3). The finding of nuclear p-Akt in basal cells of Pten-null epidermis is reminiscent of nuclear p-Akt found in neoplastic colon and prostate tissues in Pten $^{+/-} \mathrm{Pml}^{-1-}$ mice (Trotman et al. 2006). While the mechanism underlying this observation remains to be determined, our finding delineates additional isoform-specific roles and, further, suggests that $\mathrm{p} 110 \alpha$ and $\mathrm{p} 110 \beta$ isoforms play differential roles in spatially defined portions of the adult skin epidermis.

The $p 110 \alpha$ isoform is responsible for the sustained survival of suprabasal cells of epidermis in the absence of Pten, while $p 110 \beta$ is important for the hyperproliferation of basal cells in epidermal PHTS

Mammalian skin epidermis is composed of stratified epithelium with an underlying basement membrane, a single layer of proliferating basal cells, and layers of suprabasal cells that undergo differentiation in step-wise stages progressing from the spinous layer, granular layer, and outermost stratum corneum (Fuchs and Nowak 2008). Normal adult skin maintains epidermal homeostasis by balancing the proliferation, differentiation, and apoptosis of epidermal cells in these layers (Blanpain and Fuchs 2009). To examine the divergent effects of PI3K isoforms on Pten-null skin, we further analyzed skin biopsies from mice with various $p 110 /$ Pten genotypes at 8 wk of age, as described above. Keratins 5/14 (K5/K14) and $\mathrm{K} 1 / \mathrm{K} 10$ are protein markers commonly used to indicate basal and suprabasal cells, respectively. However, in Pten-null epidermis, K5 is expressed in almost the entire thickened epidermis and overlaps with $\mathrm{K} 10$ in the suprabasal layers, indicating a defective transition in the expression of these structural proteins in the basalto-suprabasal shift, when Pten is lost in the epidermis (Fig. 3A). $\Delta$ Np63, the predominant p63 isoform expressed in mature epidermis, is preferentially expressed in basal epidermis (Yang et al. 1998; Liefer et al. 2000). Immunostaining analysis revealed that $\Delta \mathrm{Np} 63$ remains as the predominant p63 isoform in Pten-null epidermis (Supplemental Fig. 4A). Notably, in the Pten-null epidermis, unlike the massive expression pattern of $\mathrm{K} 5, \Delta \mathrm{Np} 63$ positive cells display relatively modest expansion into the suprabasal space (Supplemental Fig. 4A,B). Moreover, $\Delta \mathrm{Np} 63$ and $\mathrm{K} 10$ expressions show a discrete separation in the epidermis (Supplemental Fig. 5). Many cells in these $\Delta$ Np63-positive layers are also Ki67- and BrdU-positive
(Fig. 3B,C; Supplemental Fig. 6), indicating that, in the absence of Pten, $\Delta \mathrm{Np} 63$ remains as a reliable marker for basal cells with increased proliferation capacity. Consistent with the expanded suprabasal layers of Pten-null skin as observed through K10 staining, a marked accumulation of loricrin-positive (a marker for terminally differentiated epidermal cells) cells was also found in the granular layer of the Pten-deficient skin (Fig. 3D).

Interestingly, ablation of $p 110 \alpha$ in Pten-null skin largely prevented the accumulation of K10- and loricrin-positive cells but did not significantly affect the distribution of Ki67- and $\Delta$ Np63-positive cells (Fig. 3A-D). Conversely, deletion of $p 110 \beta$ in Pten-null epidermis greatly reduced K5-positive cells and confined both Ki67- and p63-positive cells to the basal layer but still permitted abnormal accumulation of the terminally differentiated granular cells (Fig. 3A-D). Concurrent ablation of both $p 110 \alpha$ and $p 110 \beta$ isoforms restored epidermal thickness, proliferation indexes, and skin architecture in Pten-deficient epidermis to a normal state (Fig. 3A-D). Together, these findings suggest that $\mathrm{p} 110 \alpha$ is primarily responsible for the survival of differentiated suprabasal cells, while $\mathrm{p} 110 \beta$ is important for the proliferation of basal cells.

To further understand the unique, spatially distinct roles of the PI3K isoforms in the epidermis, we determined the expression pattern of these two isoforms in basal and suprabasal cells. The expression of $\alpha 6$-integrin is restricted to basal cells and has been used to sort basal and suprabasal keratinocytes (Yi et al. 2008). We also confirmed that $\alpha 6$-integrin expression is largely limited in $\Delta$ Np63-positive basal layers in Pten ${ }^{\Delta}$ epidermis. We therefore isolated skin keratinocytes and collected basal cells ( $\alpha 6$-integrin high) and suprabasal cells ( $\alpha 6$-integrin low) through fluorescence-activated cell sorting (FACS) (Supplemental Fig. 7). Real-time quantitative PCR of these cells isolated from wild-type skin revealed that the expression level of $p 110 \alpha$ in suprabasal cells is approximately fivefold higher than that of basal cells. Conversely, the expression level of $p 110 \beta$ in basal cells is approximately fivefold higher than in suprabasal cells (Fig. 3E). The cells isolated from the Pten-null skin show the same differential expression pattern of $p 110 \alpha$ and $p 110 \beta$ in basal and suprabasal cells of the epidermis (Fig. 3F). The differences were smaller than those observed in wild-type skin, perhaps due to the perturbed basal-to-suprabasal transition in the absence of Pten, leading to a possible contamination of basal cells with suprabasal cells and vice versa during cell sorting. These data suggest that the differential expression of $p 110 \alpha$ and $p 110 \beta$ in the basal and suprabasal compartments of epidermis is likely one of the mechanisms responsible for the spatially differential roles of these two p110 isoforms in skin epidermis.

A p110 $\alpha$-selective inhibitor (A66) induces cell death in the surface layers of epidermis, while a p110 $\beta$-selective inhibitor (KIN-193) reduces the proliferation of basal cells in skin PHTS

To further define the distinct roles of PI3K isoforms in established skin hamartomas, we extended our study to 


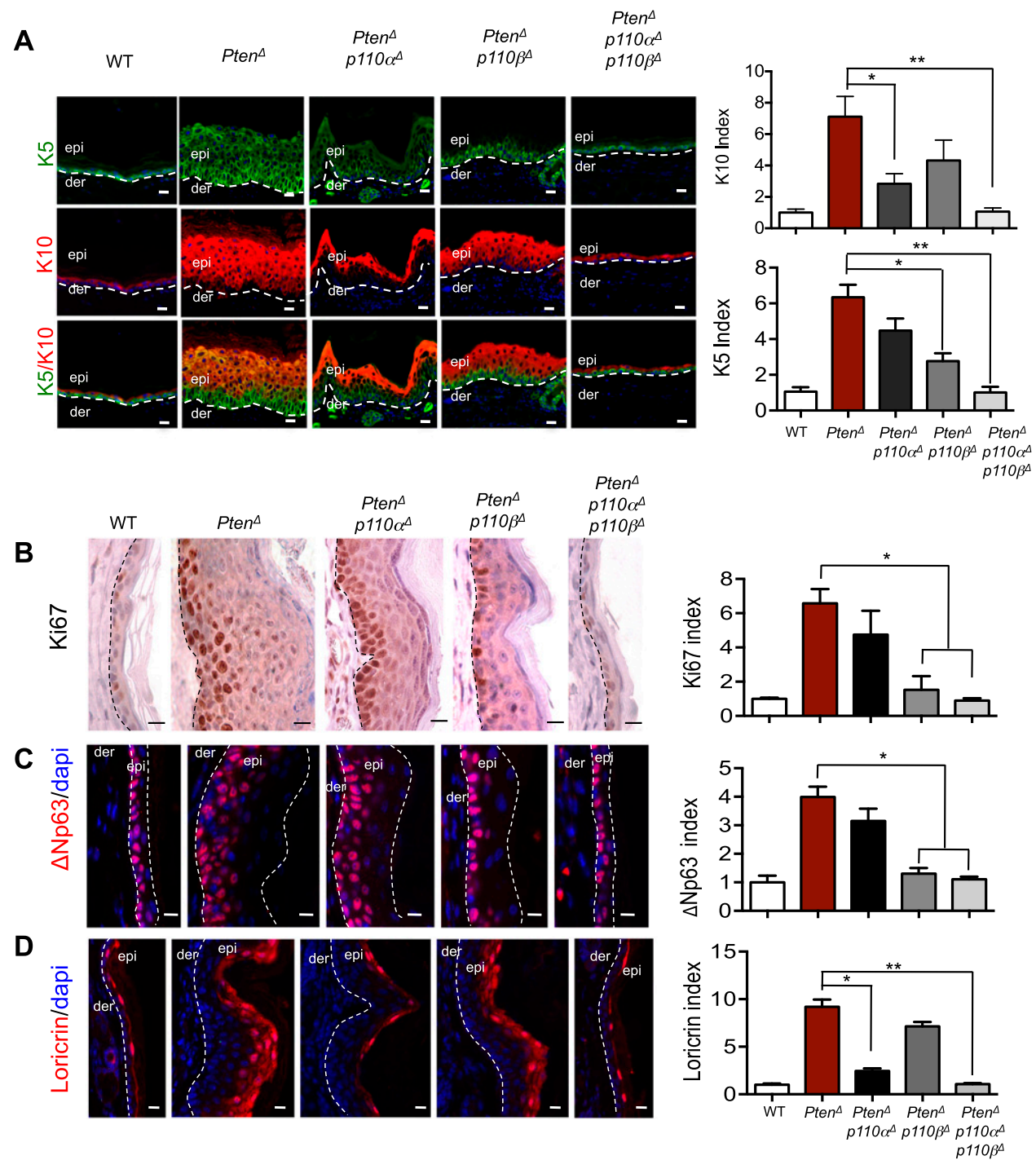

E

$\mathbf{F}$
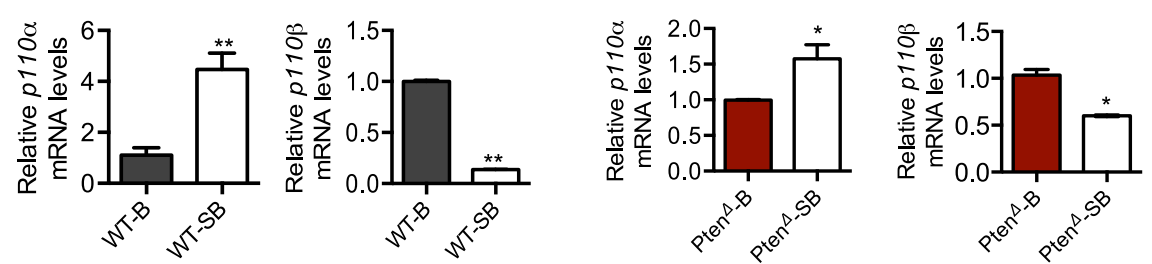

Figure 3. Divergent roles of PI3K isoforms on the skin of Pten mice. (A) Immunofluorescence (IF) staining analyses of K5 and K10 in epidermal sections from the ears of 8-wk-old mice of the indicated genotypes. Dashed lines denote the dermo/epidermal border. Bar, $20 \mu \mathrm{m}$. The number of K5- and K10-positive cells in a 100- $\mu \mathrm{m}$ length of epidermis of wild-type mice was used as a control (defined as 1). The bar graph represents the K5 or K10 index of each genotype relative to the control $\left( \pm \mathrm{SEM} ; n=6\right.$ for each genotype). $\left({ }^{\star}\right) P<0.01 ;\left({ }^{\star}\right)$ $P<0.001$ (Student's $t$-test). (B) IHC analyses of Ki67 in epidermal sections of ears from 8-wk-old mice of the indicated genotypes. Dashed lines denote the dermo/epidermal border. Bar, $20 \mu \mathrm{m}$. The number of Ki67-positive cells in a 100- $\mu \mathrm{m}$ length of epidermis of wild-type mice was used as a control (defined as 1). The bar graph represents the Ki67 index of each genotype relative to the control ( \pm SEM; $n=6$ for each genotype). $\left({ }^{\star}\right) P<0.01$ (Student's $t$-test). (C) IF staining analyses of the basal marker $\Delta$ Np63 in epidermal sections of ears from 8-wk-old mice of the indicated genotypes. (der) Dermis; (epi) epidermis. The area between the two dashed lines denotes the epidermal layer. Bar, $20 \mu \mathrm{m}$. The number of $\Delta$ Np63-positive cells in a 100- $\mu \mathrm{m}$ length of epidermis of wild-type mice was used as a control (defined as 1). The bar graph represents the $\Delta \mathrm{Np} 63$ index of each genotype relative to the control $( \pm S E M ; n=6$ for each genotype). $\left(^{\star}\right) P<0.01$ (Student's $t$-test). (D) IF staining analyses of the terminal differentiation marker loricrin in epidermal sections of ears from 8-wk-old mice of the indicated genotypes. Dashed lines denote the dermo/epidermal border. Bar, $20 \mu \mathrm{m}$. The number of loricrin-positive cells in a 100- $\mu \mathrm{m}$ length of epidermis of wild-type mice was used as a control (defined as 1). The bar graph represents the loricrin index of each genotype relative to the control ( \pm SEM; $n=6$ for each genotype). $\left({ }^{\star}\right) P<0.01 ;\left(^{\star \star}\right) P<0.001$ (Student's $t$-test). (E) Quantitative RT-PCR of $p 110 \alpha$ and $p 110 \beta$ in FACS-purified cells from ear epidermis of 8 -wk wild-type mice. (B) Basal layer; (SB) suprabasal. The relative expression level of each gene is normalized against its basal cell expression, defined as $1 .\left(^{\star}\right) P<0.01 ;\left(^{\star \star}\right) P<$ 0.001 (Student's $t$-test). (F) Quantitative RT-PCR of $p 110 \alpha$ and $p 110 \beta$ in FACS-purified cells from ear epidermis of 8-wk Pten ${ }^{\Delta}$ mice. (B) Basal layer; $(\mathrm{SB})$ suprabasal. The relative expression level of each gene is normalized against its basal cell expression, defined as $1 .\left({ }^{\star}\right) P<$ $0.01 ;\left(^{\star \star}\right) P<0.001$ (Student's $t$-test). 
pharmacological approaches, isolating skin biopsies from hamartoma-bearing Pten $^{\Delta}$ mice treated for $3 \mathrm{~d}$ with vehicle, BKM120 (a pan PI3K inhibitor) (Maira et al. 2012), A66 (a p110 $\alpha$-selective inhibitor) (Jamieson et al. 2011), and KIN-193 (a p110ß-selective inhibitor) (Ni et al. 2012). Analyses of skin sections demonstrated that, while A66 significantly reduced the number of K10-positive suprabasal cells, KIN-193 greatly reduced the number of $\Delta$ Np63-positive basal cells (Fig. 4A). Notably, BKM120 treatment reduced both $\mathrm{K} 10$ - and $\Delta \mathrm{Np} 63$-positive cells in the thickened Pten-null epidermis (Fig. 4A). Further analyses of these skin sections showed that, while A66 eliminated the majority of p-Akt in the outer layer cells, KIN-193 reduced p-Akt - in particular, nuclear p-Akt-in basal layer cells, and BKM120 almost completely abolished p-Akt in Pten-null skin (Fig. 4B; Supplemental Fig. 8), mirroring the genetic findings described above. Moreover, we found that A66 selectively induced cell death of loricrin-positive granular cells but had little effect on the proliferative capacity of the basal layer cells (Fig. 4C,D; Supplemental Fig. 9). In contrast, KIN-193 significantly reduced the number of Ki67-positive cells in basal layers but failed to induce cell death of granular cells (Fig. 4C,D; Supplemental Fig. 9). Consistently, BKM120 treatment markedly reduced Ki67-positive cells in the basal layer and greatly increased numbers of TUNEL-positive cells in the granular layer of epidermis as compared with those from vehicle controls (Fig. 4C,4D; Supplemental Fig. 9). Together, these pharmacological results are consistent with our genetic data and further support the spatially differential roles of $\mathrm{p} 110 \alpha$ and $\mathrm{p} 110 \beta$ in skin epidermis.

Previous studies have demonstrated that the p110 $\alpha$ isoform mediates RTK signaling, and the p110 $\beta$ isoform engages GPCR signaling (Vanhaesebroeck et al. 1997; Zhao et al. 2005; Jia et al. 2008; Kroeze et al. 2012; Utermark et al. 2012). We therefore sought to determine whether the specific roles of p110 isoforms in epidermislacing Pten are differentially regulated by upstream signals that mediate the activation of $\mathrm{PI} 3 \mathrm{~K}$; e.g., growth factors and chemokines. We treated hamartoma-bearing mice with RTK inhibitors (a combination of lapatinib and sunitinib to achieve inhibition of a broad spectrum of RTKs) or a general GPCR signaling inhibitor (pertussis toxin) and harvested the skin specimens for analysis $3 \mathrm{~d}$ after treatment. IHC staining for p-Akt revealed that the treatment with RTK inhibitors reduced p-Akt in suprabasal cells, while the treatment with the GPCR signaling inhibitor reduced p-Akt in basal layer cells (Fig. 4E). Moreover, we showed that RTK inhibitors induced apoptosis of granular cells, whereas GPCR inhibitor suppressed proliferation of basal cells (Fig. 4F,G). In addition, we found that cells expressing CXCR3 (a member of the GPCR family) are tightly clustered with basal cells that express high $\alpha 6$-integrin in both wild-type and Pten-null skin (Supplemental Fig. 10), consistent with a previous finding that CXCR3 is highly enriched in basal cells (Kroeze et al. 2012). Together, the differences in the upstream regulation of the PI3K signaling in different regions of the epidermis may act in concert with the differential expressions of the two isoforms in the skin layers, providing a potential molecular mechanism underlying the spatially distinct roles of p110 $\alpha$ and $\mathrm{p} 110 \beta$ isoforms in the epidermis.

\section{A pan-PI3K inhibitor, BKM120, is able to prevent the development of skin PHTS}

Since our genetic studies suggest that uncontrolled PI3K activity of both isoforms is responsible for the development of skin harmotomas in the absence of Pten, we hypothesized that pharmacological inhibition of class Ia PI3K activity might interfere with the initiation of PTHS in mice. We therefore tested the effects of BKM120, a panclass I PI3K inhibitor currently in clinical trials for cancer therapy (Maira et al. 2012). We treated Pten $^{\Delta}$ mice at $3 \mathrm{wk}$ of age with various doses of BKM120 and isolated epidermal tissues for Western blot analysis of p-Akt to assess the inhibitory effects of this drug. A relatively low dose of BKM120 $(25 \mathrm{mg} / \mathrm{kg})$ reduced p-Akt levels in keratinocytes of Pten $^{\Delta}$ mice to baseline levels (Supplemental Fig. 11). We then subjected cohorts of Pten ${ }^{\Delta}$ mice to daily treatments with $25 \mathrm{mg} / \mathrm{kg}$ BKM120 $(n=14)$ or vehicle $(n=12)$ beginning at 3 wk of age. As expected, all mice in the vehicle control group progressively developed various skin lesions within $60 \mathrm{~d}$ (Fig. 5A; Supplemental Fig. 12). Remarkably, all mice in the treatment group were free of skin lesions during the entire 11-wk course of treatment (Fig. 5; Supplemental Fig. 12). However, when BKM120 was withdrawn from six mice in the BKM120 treatment group at the end of the 11 th week, all six developed skin lesions within a week (Fig. 5; Supplemental Fig. 12). In contrast, the remaining eight mice in the cohort, which were maintained on BKM120 treatment, remained symptom-free (Fig. 5A; Supplemental Fig. 12), suggesting that continuous drug treatment is required to prevent the development of PHTS. Accordingly, histological analyses of skin samples from the faces and paws of mice at the end of the treatment course demonstrated that normal skin thickness and architecture were maintained in mice treated with BKM120 (Fig. 5C). Our data indicate that a submaximal and well-tolerated dose of a pan-class Ia PI3K inhibitor can offset the excessive proliferation of epidermal cells and prevent the survival/accumulation of terminally differentiated epidermal cells in the absence of Pten, thereby maintaining normal skin morphology and minimizing the phenotypic consequences of Pten deficiency.

\section{BKM120 is able to reverse skin PHTS that has reached} advanced stages in mice

Since inhibition of $p 110 \alpha$ promotes cell death of accumulated outer layer epidermal cells and inhibition of $p 110 \beta$ suppresses hyperproliferation of inner layer basal cells on PHTS skin, we hypothesized that combined inactivation of both $\mathrm{p} 110 \alpha$ and $\mathrm{p} 110 \beta$ using a pan-PI3K inhibitor might induce regression of hamartomas in Ptendeficient epidermis and alleviate disease symptoms in adult mice with established PHTS. Using Pten ${ }^{\Delta}$ mice that had developed advanced multiple skin hamartomas, a clinically relevant dose of BKM120 (45 mg/kg) was 


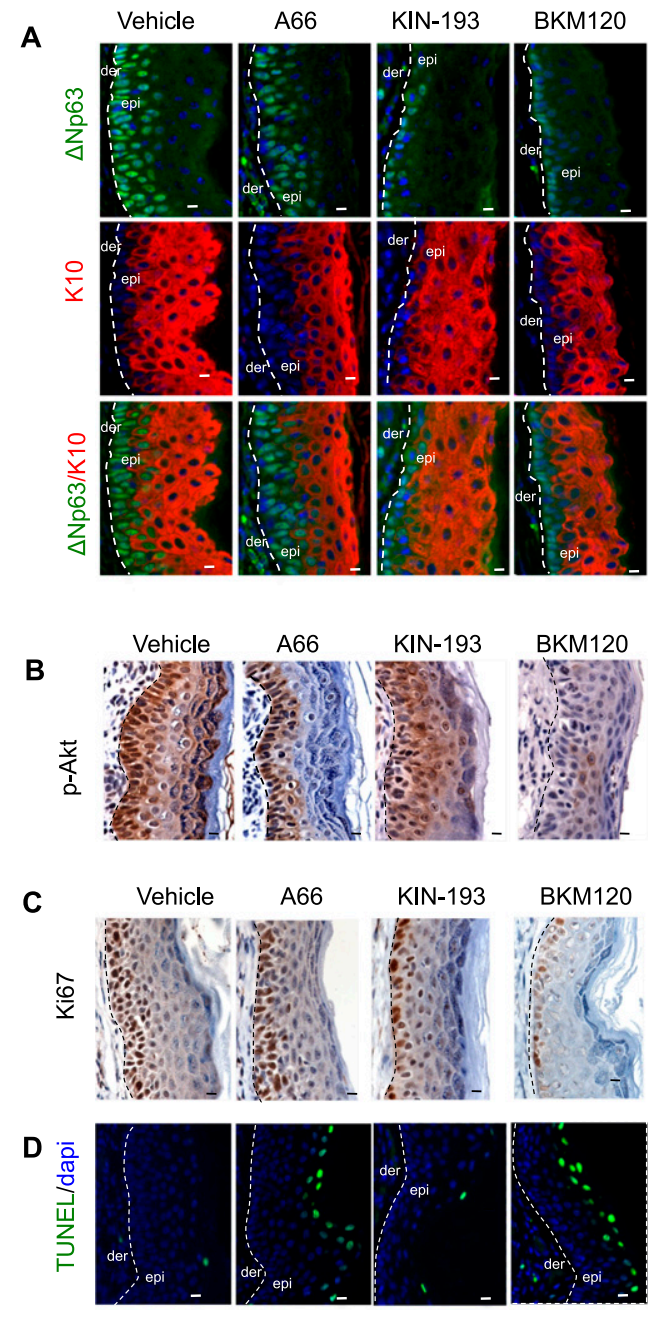

E

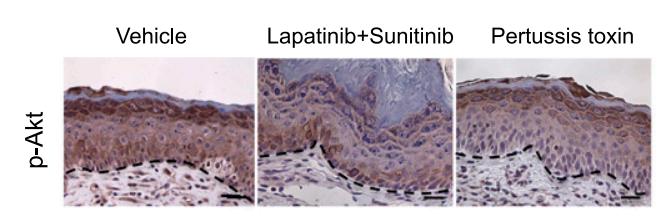

$\mathbf{F}$

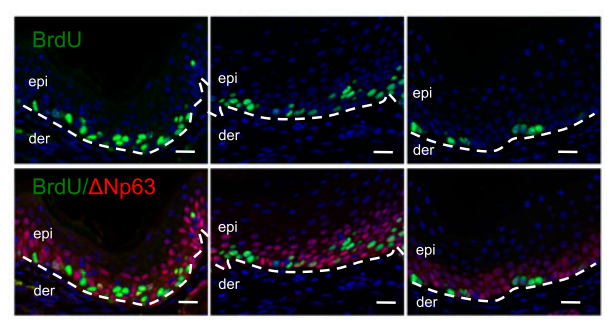

G

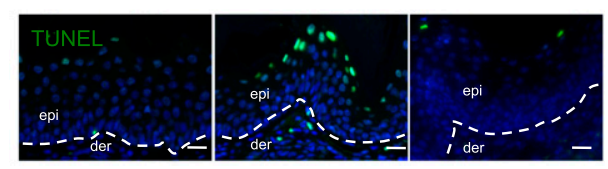

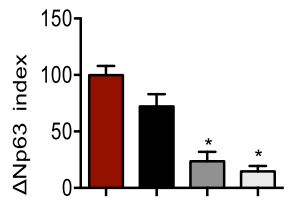
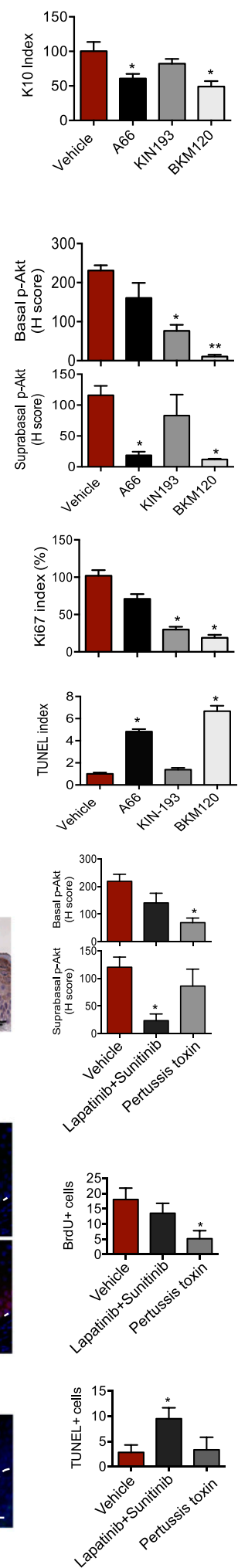

Figure 4. Effects of $\mathrm{p} 110 \alpha$-selective inhibitor (A66) and p110ß-selective inhibitor (KIN-193) on PHTS of Pten ${ }^{\Delta}$ mice. (A) IF staining analyses of $\Delta \mathrm{Np} 63$ and $\mathrm{K} 10$ in epidermal sections of ears from hamartoma-bearing Pten $^{\Delta}$ mice $3 \mathrm{~d}$ after treatment with vehicle, A66 $(100 \mathrm{mg} / \mathrm{kg}$, once per day [QD]), KIN-193 (20 mg/kg, twice per day [BID]), or BKM120 (45 mg/kg, QD). Dashed lines denote the dermo/epidermal border. Bar, $20 \mu \mathrm{m}$. The number of $\Delta$ Np63- and K10-positive cells in a $100-\mu \mathrm{m}$ length of epidermis of wild-type mice was used as a control (defined as 1). The bar graph represents the $\Delta \mathrm{Np} 63$ or K10 index of each genotype relative to the control $( \pm S E M ; n=6$ for each genotype). $\left({ }^{\star}\right) P<0.01$ (Student's $t$-test). (B) IHC analysis of p-Akt in epidermal sections of ears from hamartoma-bearing Pten ${ }^{\Delta}$ mice $3 \mathrm{~d}$ after treatment with vehicle, A66 (100 mg/kg, QD), KIN-193 (20 mg/kg, BID), or BKM120 (45 mg/kg, QD). Dashed lines mark the epidermal-dermal junction. Bar, $20 \mu \mathrm{m}$. H-scores of p-Akt in basal and suprabasal epidermis are shown as mean $\left.\pm \operatorname{SEM}(n=6) .{ }^{\star}\right) P<0.01 ;\left({ }^{\star \star}\right) P<0.001$ (Student's $t$-test). (C) IHC analysis of Ki67 in the epidermal sections of ears from hamartoma-bearing Pten ${ }^{\Delta}$ mice $3 \mathrm{~d}$ after treatment with vehicle, A66 (100 mg/kg, QD), KIN-193 (20 mg/kg, BID), or BKM120 (45 mg/kg, QD). Bar, $10 \mu \mathrm{m}$. The dashed line indicates the boundary between epidermis and dermis. The number of Ki67-positive cells in a 100- $\mu \mathrm{m}$ length of epidermis of $\mathrm{Pten}^{\Delta}$ mice treated with vehicle was used as a control (defined as $100 \%$ ). The bar graph shows the Ki67 index of each group of mice expressed as percentage of the control $( \pm$ SEM; $n=6$ for each genotype). $\left(^{\star}\right) P<0.01$ (Student's $t$-test). (D) TUNEL assay of epidermal sections of ears from hamartomabearing Pten $^{\Delta}$ mice $3 \mathrm{~d}$ after treatment with vehicle, A66 (100 mg/kg, QD), KIN-193 (20 mg/kg, BID), or BKM120 (45 mg/kg, QD). The dashed line indicates the boundary between epidermis and dermis. The number of TUNEL-positive cells in a $100-\mu \mathrm{m}$ length of epidermis of Pten $^{\Delta}$ mice treated with vehicle was used as a control (defined as 1). The bar graph shows the TUNEL index of each group of mice expressed as percentage $( \pm$ SEM) over the control $\left(n=6\right.$ for each genotype). Bar, $10 \mu \mathrm{m} .\left(^{\star}\right) P<$ 0.001 (Student's $t$-test). (E) IHC analysis of p-Akt in epidermal sections of ears from hamartoma-bearing Pten $^{\Delta}$ mice $3 \mathrm{~d}$ after treatment with vehicle, a combination of lapatinib (100 mg/kg, QD) and sunitinib (40 mg/kg, QD), or pertussis toxin $(20 \mu \mathrm{g} / \mathrm{kg}$, QD). Dashed lines mark the epidermal-dermal junction. Bar, $20 \mu \mathrm{m}$. H-scores of p-Akt in basal and suprabasal epidermis are shown as mean \pm SEM $(n=6) .\left(^{*}\right) P<0.01$ (Student's $t$-test). $(F)$ IF staining analyses of BrdU-positive cells and $\Delta \mathrm{Np} 63$-positive cells in epidermal sections of ears from hamartoma-bearing $P_{t e n}{ }^{\Delta}$ mice $3 \mathrm{~d}$ after treatment with vehicle, a combination of lapatinib (100 mg/kg, QD) and sunitinib (40 mg/kg, QD), or pertussis toxin $(20 \mu \mathrm{g} / \mathrm{kg}$, QD). Dashed lines denote the dermo/epidermal border. Bar, $20 \mu \mathrm{m}$. The number of BrdU-positive cells in a 100- $\mu \mathrm{m}$ length of epidermis of mice as indicated. ( \pm SEM; $n=6) .\left({ }^{\star}\right) P<0.01$ (Student's $t$-test). $(G)$ TUNEL assay of epidermal sections of ears from hamartoma-bearing Pten ${ }^{\Delta}$ mice $3 \mathrm{~d}$ after treatment with vehicle, a combination of lapatinib (100 $\mathrm{mg} / \mathrm{kg}, \mathrm{QD}$ ) and sunitinib (40 mg/ $\mathrm{kg}$, QD), or pertussis toxin $(20 \mu \mathrm{g} / \mathrm{kg}, \mathrm{QD})$. The dashed line indicates the boundary between epidermis and dermis. The number of TUNEL-positive cells in a 100- $\mu \mathrm{m}$ length of epidermis of $P$ ten ${ }^{\Delta}$ mice. Bar, $20 \mu \mathrm{m} .\left(^{\star}\right) P<0.01$ (Student's $t$-test). 

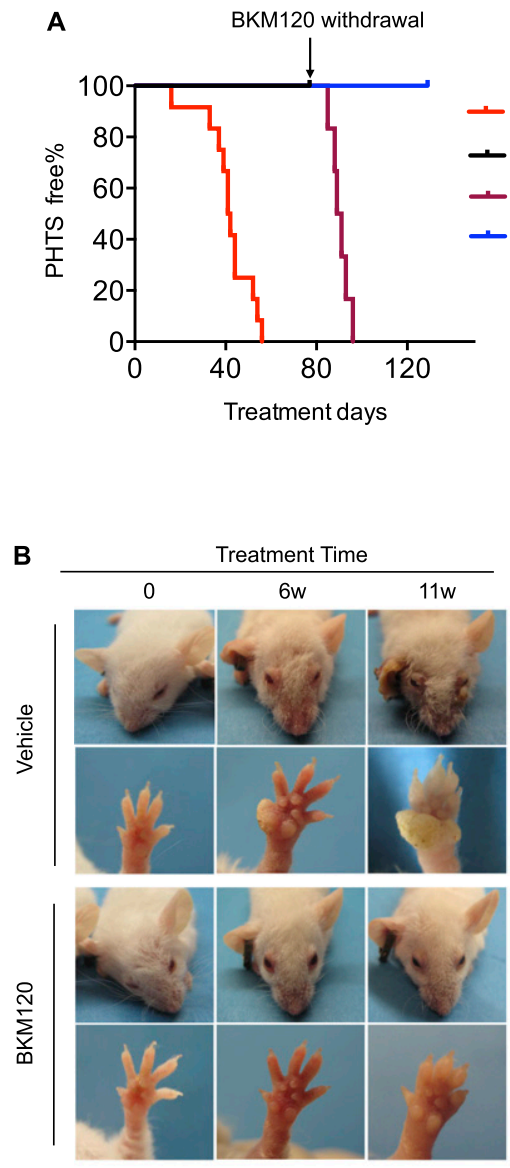

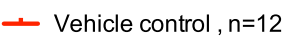

- BKM120, $n=14$

- BKM120 withdrawal, $\mathrm{n}=6$

- BKM120 continued, $\mathrm{n}=8$

C

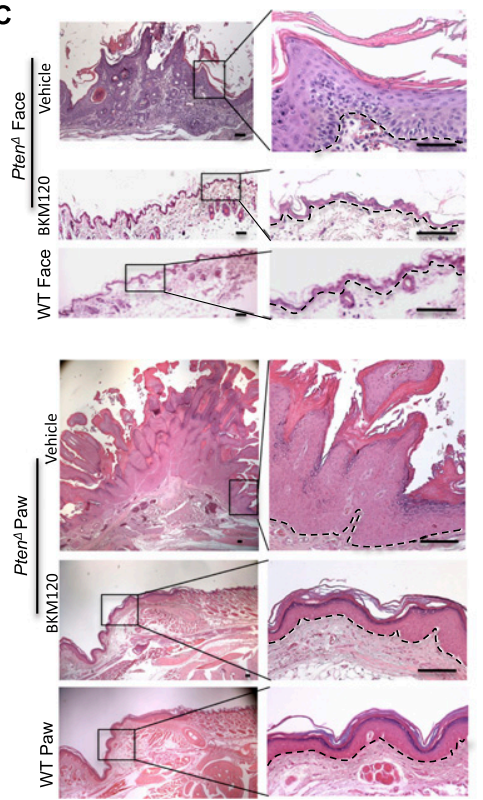

Figure 5. Early administration of BKM120 prevents the development of skin PHTS in mice. (A) KM curves for Pten ${ }^{\Delta}$ mice treated with BKM120 (25 mg/kg, QD) (black line; $n=14$ ) or vehicle only (red line, $n=12$ ) starting at $3 \mathrm{wk}$ of age. BKM120 was withdrawn from six of BKM120-treated mice at the end of the 11th week of treatment as shown by the dark-red line. BKM120 treatment was continued for the remaining eight mice for an additional $6 \mathrm{wk}$, as shown by the blue line. $(B)$ Representative photos showing the appearance of the faces and paws of $\operatorname{Pten}^{\Delta}$ mice at 6 and 11 wk post-treatment with vehicle or BKM120 (25 mg/kg, QD). Treatment was started at $3 \mathrm{wk}$ of age. $(C)$ Representative $\mathrm{H} \& \mathrm{E}$ staining of tissue sections of face skin and paw regions from $\mathrm{Pten}^{\Delta}$ mice upon completion of $11 \mathrm{wk}$ of treatment with vehicle or BKM120 (25 mg/kg, QD) beginning at 3 wk of age. Dashed lines denote the dermo/epidermal border. Bar, $100 \mu \mathrm{m}$. administered daily, and mice were monitored for morphological skin changes. We confirmed by Western blot analyses that BKM120 administered at $45 \mathrm{mg} / \mathrm{kg}$ abrogated p-Akt levels signals in Pten-deficient hamartoma epidermis (Supplemental Fig. 13). Our initial study was performed on a small cohort of $\mathrm{Pten}^{\Delta}$ mice consisting of only two mice with advanced skin hamartomas. Prior to treatment, mouse \#J845 (15 wk old) displayed severe skin lesions associated with hyperkertosis on its face and paws (Fig. 6A). Remarkably, the facial lesions on this mouse disappeared, and the papillomas on its paw were dramatically reduced after 2 wk of BKM120 treatment; the skin conditions continued to improve up to $4 \mathrm{wk}$ of treatment (Fig. 6A). Similarly encouraging results were observed on mouse \#J596 (14 wk old) after treatment with this PI3K inhibitor. A large tumor that had developed on the left ear shrank dramatically after 2 wk of BKM120 treatment; after $4 \mathrm{wk}$ of treatment, this tumor was completely eradicated (Fig. 6A). We conducted the same treatment regimen on a group of six Pten $^{\Delta}$ mice (between 12 and 16 wk of age) bearing severe PHTS on their faces, ears, and paws. Extraordinarily, BKM120 treatment led to rapid regression of all skin lesions on the faces, ears, and paws of treated mice. Significant morphological changes in these mice started to manifest 1 wk after the treatment, and their skin condition continued to improve, reaching a near-normal state after 4 wk of treatment (Fig. 6A; Supplemental Fig. 14). Consistent with these findings, histological analyses of skin biopsies from the faces and paws of PHTS-bearing mice before and after treatment demonstrated that the drug resulted in a dramatic transformation in these mice, with skin progressing from a disordered condition to a near-normal state as assessed by histology and various molecular staining, including $\Delta$ Np63/K10, p-Akt, and Ki67 (Fig. 6B; Supplemental Fig. 15). Thus, continuously up-regulated PI3K activity appears to be essential for the maintenance of these skin hamartomas induced by Pten loss, and pharmacological inhibition of class I PI3K activity effectively reverses PHTS in mice.

\section{Discussion}

Our studies using genetic mouse models revealed that a balance between PI3K and Pten activity is critical in skin homeostasis. While Pten functions as a dual protein/ lipid phosphatase and has also been found to have phosphatase-independent modes of action, we showed that loss of its lipid phosphatase activity in particular is largely responsible for its role in skin PHTS. The consequences of the loss of Pten activity can be suppressed or reversed through genetic ablation of $p 110 \alpha$ and $p 110 \beta$ 

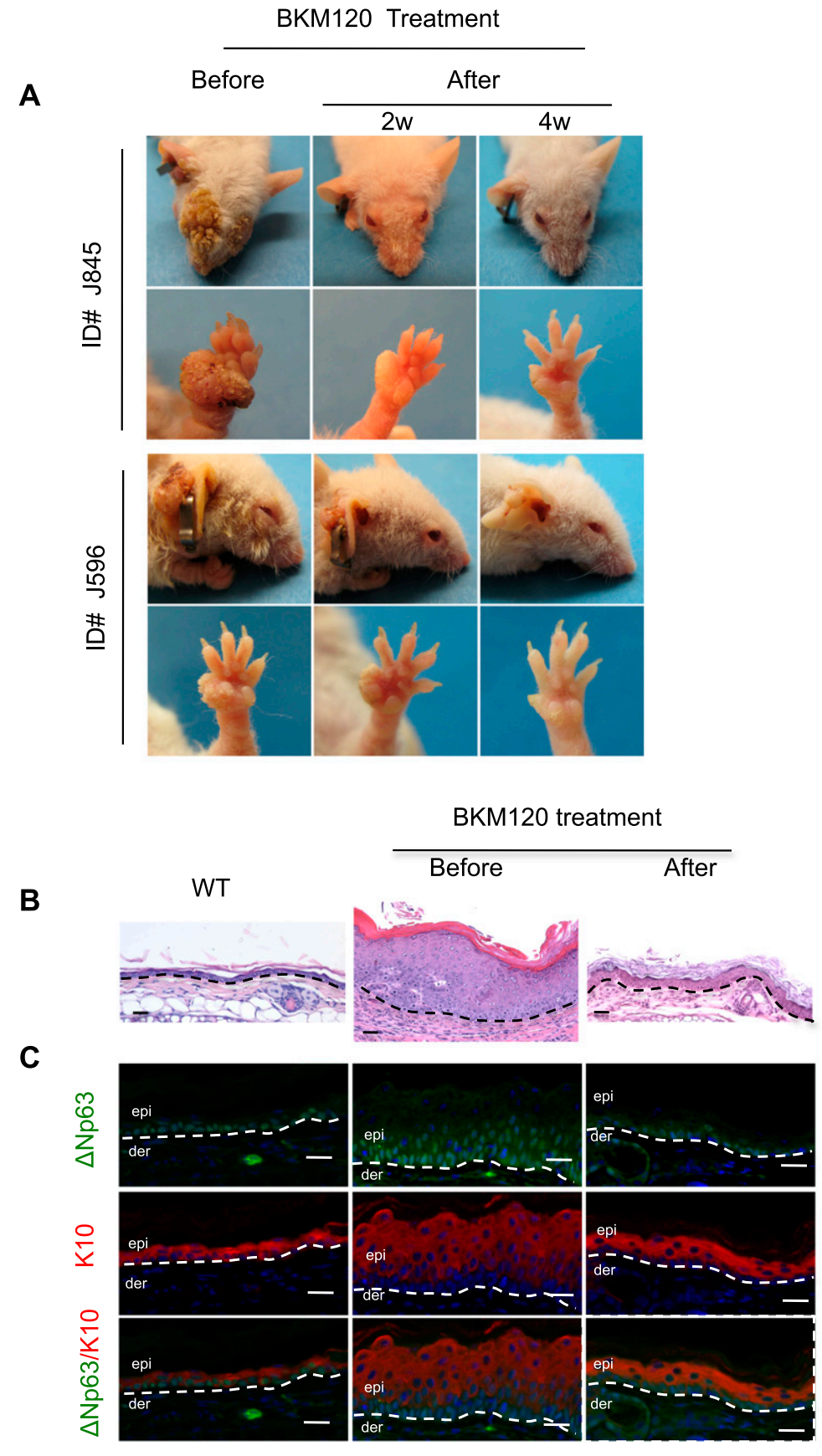

Figure 6. Administration of BKM120 relieves PHTS in $\mathrm{Pten}^{\Delta}$ mice. Hamartoma-bearing $\mathrm{Pten}^{\Delta}$ mice were treated with vehicle or BKM120 (45 mg/kg, QD) for 4 wk. (A) Representative images of two Pten ${ }^{\Delta}$ mice (ID \#J845 and \#J596) before and after 2 wk and 4 wk of treatment with BKM120. (B) Representative H\&E staining of tissue sections of ears from hamartoma-bearing Pten $^{\Delta}$ mice before and after 4 wk of treatment with BKM120 (45 mg/kg, QD). Dashed lines denote the dermo/epidermal border. Bar, $20 \mu \mathrm{m}$. (C) IF staining analyses of $\Delta \mathrm{Np} 63$ and $\mathrm{K} 10$ in epidermal sections of ears from hamartoma-bearing Pten $^{\Delta}$ mice treated with vehicle or BKM120 (45 mg/kg, QD) for 4 wk. Dashed lines denote the dermo/epidermal border. Bar, $20 \mu \mathrm{m}$. isoforms of class Ia PI3K or by their pharmacological inhibition via a pan-class I PI3K inhibitor. The more nuanced roles of the two commonly expressed PI3K isoforms in skin contrasts with our previous findings that ablation of $p 110 \beta$ was sufficient to block Pten loss-induced PIN in the anterior lobes of mouse prostates (Jia et al. 2008).

Here we report an interesting and surprising "division of labor" in a spatially defined manner between the two isoforms in maintaining skin epithelium, as depicted in the diagram in Figure 7A. The unique cellular architecture of the Pten-null epidermis, dramatically thickened skin, and increased epidermal layers, provide us with an exceptional platform to determine the role that $\mathrm{p} 110 \alpha$ or p1 $10 \beta$ activity plays in PHTS by examining the consequences of their inhibition either genetically or pharmacologically (Fig. 7B). In the Pten-null epidermis where p1 $10 \alpha$ is also genetically or pharmacologically inactivated, $\mathrm{p} 110 \beta$ becomes the major PI3K player that is unrestrained by its lipid phosphatase, resulting in a hyperproliferative epithelium featuring an expansion of its basal cell layers (Fig. 7B, third panel). In contrast, when Pten and $\mathrm{p} 110 \beta$ are absent in the epidermis, uncontrolled p1 $10 \alpha$ activity sustains survival of terminally differentiated cells such that these cells fail to undergo apoptosis 
A

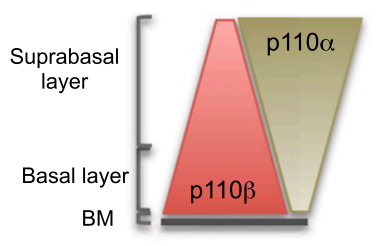

B

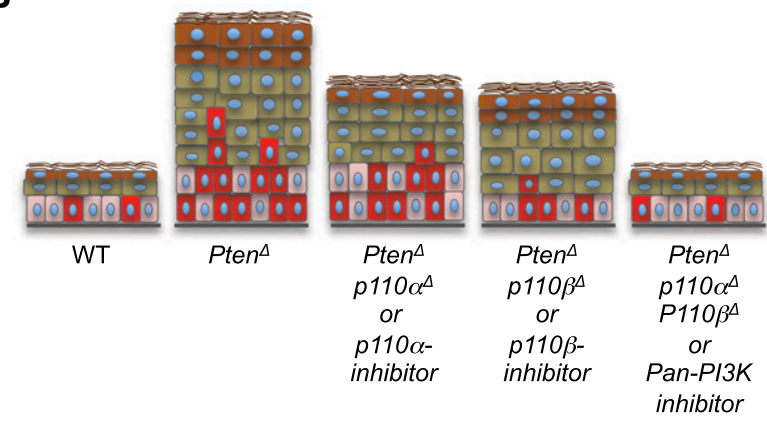

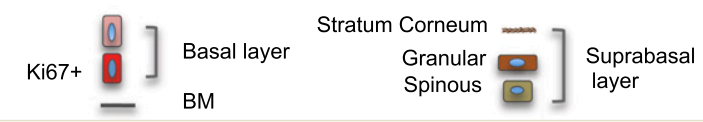

Figure 7. (A) Summary of spatially differential roles of $\mathrm{p} 110 \alpha$ and $\mathrm{p} 110 \beta$ isoforms in skin epidermis. $(B)$ Diagram representation of skin histology in mice and the extent of p110 's and p110 $\beta^{\prime}$ s role in the epidermis lacking Pten.

as they reach the skin surface, resulting in the accumulation of terminally differentiated suprabasal cells (Fig. $7 \mathrm{~B}$, fourth panel). The PHTS skin can only be restored to normal by suppressing both PI3K isoforms. Thus, Pten has an essential role in counterbalancing the kinase activities of both p110 isoforms to maintain skin homeostasis and prevent the development of PHTS.

While our finding of the spatially differential expression patterns of $p 110 \alpha$ and $p 110 \beta$ provides a mechanistic understanding of the specific roles of these two isoforms in epidermis, clearly, additional factors are also at play in the regulation of these PI3K isoforms in the skin epidermis. Since Pten loss simply removes a "brake" from the PI3K pathway, the specific roles of p110 isoforms in various pathogenic states induced by Pten loss can be influenced by tissue microenvironment cues that mediate the activation of PI3K; e.g., growth factors, chemokines, extracellular matrix proteins, and other input signals. Indeed, we found that broad-spectrum inhibition of RTKs resulted in reduced p-Akt in suprabasal cells and increased apoptosis of granular cells in Pten-deficient skin. Conversely, a general GPCR signaling inhibitor (pertussis toxin) largely reduced Akt phosphorylation and cell proliferation in basal cells of Pten-null epidermis. Thus, the p1 $10 \alpha$-dependent signal is likely due to activation of an RTK in the suprabasal layers, while the p110ß-dependent signaling likely arises from either GPCR or integrin-mediated signaling or both. Notably, in the skin, only basal cells contact the basement membrane and hence feature integrin engagement. However, precisely how diverse signals activate certain PI3K isoforms and how these activities are coordinated with each other and with Pten to control this pathway in different tissues and cell types remain to be determined.

Importantly, our work holds potential for translating insights from mouse genetics into human therapy. Emerging from our study is the potential benefit of pharmacological PI3K inhibitors for PHTS patients as both therapeutic agents and chemopreventive agents (at reduced doses) with meaningful clinical outcomes. The newly identified spatially divergent roles for $\mathrm{p} 110 \alpha$ and $\mathrm{p} 110 \beta$ in skin suggest that the use of PI3K inhibitors to treat these skin lesions can be versatile. For example, if long-term systemic use of a pan-inhibitor proved to have adverse metabolic effects even at the low doses that we found beneficial in mice, one might take a combination approach using topical application of a p110 $\alpha$ inhibitor with the systemic administration of a drug directed against p110 $\beta$. Since $\mathrm{p} 110 \alpha$ is essential for the metabolic functions of insulin and for glucose homeostasis (Sopasakis et al. 2010), external application may provide safer and more effective therapy for PHTS patients.

\section{Materials and methods}

\section{Mice}

K14Cre (Jonkers et al. 2001), Pten ${ }^{L / L}$ (Lesche et al. 2002), $p 110 \alpha^{L / L}$ (Zhao et al. 2006), and $p 110 \beta^{L / L}$ (Jia et al. 2008) mice were backcrossed 10 generations to the $\mathrm{FVB} / \mathrm{N}$ background before being intercrossed to generate experimental mice for this study. All animals were housed and treated in accordance with protocols approved by the Institutional Animal Care and Use Committees at Dana-Farber Cancer Institute and Harvard Medical School.

\section{PHTS severity score}

The progression of mucocutaneous lesions in mice was monitored according to the operational diagnosis criteria of PHTS (Nelen et al. 1996; Eng 2000; Laury et al. 2011). The facial papillomatous, acral keratoses, and palmoplanta keratoses (limbs and paws) were each graded from 0 (normal) to 4 (severe), and a summed score was calculated accordingly. Each grade was assigned by histological assessment. The skin samples, which were graded $>2$ in each area, were diagnosed as papilloma, a benign skin hamartoma. Papillomas in more than two areas in the body, or a summed score of 4 , were considered PHTS.

\section{Histology, IHC, and immunofluorescence (IF)}

For histology analyses, formalin-fixed tissue sections were embedded in paraffin, sectioned, and stained with hematoxylin and eosin by the Dana Farber/Harvard Cancer Center Rodent Histopathology Core. Antibodies used for IHC and IF were Ki67 (Vector Laboratories), p-Akt (Cell Signaling), p63 (Santa Cruz Biotechnology), $\Delta \mathrm{Np} 63$ (Biolegend), loricrin (Abcam), K5 (Convance), K10 (Convance), and rat anti-BrdU (AbD seroTec). For BrdU analysis, mice were injected with $50 \mathrm{mg}$ BrdU per kilogram 
of body weight $2 \mathrm{~h}$ prior to sacrifice. For IF staining, after incubation with the primary antibody, the secondary antibodies conjugated to different Alexa-Fluor dyes (488 and 594) were applied at a dilution of 1:1000 in PBS. For nuclear counterstaining, DAPI was used. TUNEL assays were performed with the In Situ Cell Death Detection kit (Roche) according to the manufacturer's instructions. Samples were then counterstained with DAPI and analyzed under a fluorescent microscope. For quantification of IHC and IF, six images were taken per skin section, and the positive cells were counted.

\section{Quantification of $p$-Akt}

Quantification of p-Akt in IHC analyses was performed using CellVigene (VigeneTech, Inc,) protocols. The RGB colors were deconvoluted to haem (blue) and dab (brown). The haem component was used to identify nuclei. The dab component was used to quantify nuclear, cytoplasmic, and total p-Akt in basal and suprabasal regions. Background subtraction was applied to each image to minimize overstaining effects. The background values were determined by drawing a region outside the basal and suprabasal areas that CellVigene software uses to autodetermine the background value in the region. The basal and suprabasal regions were classified using supervised machine learning. Typical four-level histogram scoring and mean nuclear and cytoplasmic intensities were used to calculate the percentage of a score level. A histogram score (H-score), which was equal to $1 \times(1+) \%+2 \times(2+) \%+3 \times(3+) \%$, ranging from 0 to 300 , was used to measure p-Akt.

\section{Western blotting}

Primary keratinocytes were isolated as described (Dlugosz et al. 1995). Briefly, nonhairy ear skin from mice was washed in betadine and $70 \%$ ethanol. The two skin flaps of each ear were separated carefully and trypsinized for $1.5 \mathrm{~h}$ by floating on $1 \%$ trypsin at $37^{\circ} \mathrm{C}$. The epidermis was scraped off the dermis. Cells of epidermis were then lysed in 1\% Nonidet P-40 lysis buffer supplemented with protease and phosphatase inhibitors (Roche). Equal amounts of proteins were resolved on SDS-PAGE gels and transferred to nitrocellulose membranes for Western blot analysis. The primary antibodies used were p-Akt (Ser473), p-Akt (Thr308), Akt, p110 $\alpha$, p110 $\beta$, and Pten (all from Cell Signaling Technology). Immunofluorescently labeled anti-mouse IgG (Rockland Immunochemicals) and anti-rabbit IgG (Molecular Probes) were used to visualize Western blots on an Odyssey scanner (Li-Cor). Quantification of band intensities was performed using Odyssey 3.0 software.

\section{FACS analysis}

Keratinocytes were isolated from the ear epidermis of 8 -wk-old wild-type or Pten ${ }^{\Delta}$ mice. Single-cell suspensions in PBS containing $2 \%$ FCS were incubated with primary antibodies for $30 \mathrm{~min}$ on ice prior to FACS analysis. Primary antibodies used for FACS analysis were APC $\alpha 6$-integrin antibody (R\&D Systems) and PE anti-mouse CXCR3 (Biolegend). Cell sorting was performed with BD FACSAria IIu and analyzed with FACSDiva software or FlowJo.

\section{Quantitative RT-PCR}

Total RNAs were extracted from epidermal cells using TRIzol reagent and used to synthesize cDNA with SuperScript III first strand synthesis kit (Invitrogen). Quantitative PCR reactions were performed with SYBR Green PCR Master Mix (Applied
Biosystems). Primer sequences of $p 110 \alpha$ (NM_008839) were as follows: forward, 5' -TTCTCTGGAAACTGCAGACC-3'; and reverse, $5^{\prime}$-GTGGACAGCATCCCTGTAAC- $3^{\prime}$. Primers for $p 110 \beta$ were purchased from SAbioscience (PPM05089A). The levels of amplified transcripts were normalized to that of control transcript 18s rRNA (Bouras et al. 2008).

\section{Inhibitor administration}

BKM120 (Novartis Pharmaceuticals) was reconstituted in 1 vol of NMP (1-methyl-2 pyrrolidone; Sigma) and 9 vol of PEG-300 (polyethylene glycol 300; Fluka Analytical) (Maira et al. 2012). Mice were dosed with this compound formulation at 25 or $45 \mathrm{mg} / \mathrm{kg}$ once per day (QD) by oral gavage. A66 was administered in 10\% 2-hyroxypropyl- $\beta$-cyclodextrin (Sigma-Aldrich) in water as described (Jamieson et al. 2011). Mice were dosed with $100 \mathrm{mg} / \mathrm{kg}$ QD by intraperitoneal (IP) injection. KIN-193 was dissolved in 7.5\% NMP and 40\% PEG400 (polyethylene glycol 300; Fluka Analytical) as described (Ni et al. 2012). Mice were dosed with $20 \mathrm{mg} / \mathrm{kg}$ twice per day (BID) by IP injection. Lapatinib was dissolved in $0.5 \%$ hydroxypropyl methylcellulose and $1 \%$ Tween 80 as described (Konecny et al. 2006). Sunitinib (Sigma Aldrich) was prepared in dextrose water (Zhang et al. 2009). Mice were gavaged with lapatinib (100 mg/kg) and sunitinib (40 mg/kg) QD (Sun et al. 2011). Pertussis toxin (Sigma Aldrich) was dissolved in PBS. Mice were dosed with $20 \mu \mathrm{g} / \mathrm{kg}$ QD by IP injection as described (Chen et al. 2007).

\section{Statistics}

Comparison of the Kaplan-Meier analyses was performed with the log-rank test. For all bar graphs, the Student's $t$-test was used to determine a $P$-value, and data are presented as mean \pm SEM.

\section{Acknowledgments}

We thank T.M. Roberts, L.C. Cantley, P.P. Pandolfi, and D.M. Livingston for scientific discussions, and L.K. Clayton for critical reading. We thank A. Ang, P. Liu, and M. Pusung for technical assistance. K14Cre mice were generously provided by J. Jonkers at the Netherlands Cancer Institute, Netherlands. Floxed Pten mice were generously provided by $\mathrm{H}$. Wu at the University of California at Los Angeles School of Medicine. This work was supported by NIH grants CA134502 (to J.J.Z.) and CA172461-01 (to J.J.Z.), Stand Up To Cancer (SU2C-AACR-DT0209) (to J.J.Z.), and the Department of Defense (BC112689 to J.J.Z.).

\section{References}

Backman SA, Ghazarian D, So K, Sanchez O, Wagner KU, Hennighausen L, Suzuki A, Tsao MS, Chapman WB, Stambolic V, et al. 2004. Early onset of neoplasia in the prostate and skin of mice with tissue-specific deletion of Pten. Proc Natl Acad Sci 101: 1725-1730.

Berenjeno IM, Guillermet-Guibert J, Pearce W, Gray A, Fleming S, Vanhaesebroeck B. 2012. Both p110 $\alpha$ and p1 $10 \beta$ isoforms of PI3K can modulate the impact of loss-of-function of the PTEN tumour suppressor. Biochem J 442: 151-159.

Blanpain C, Fuchs E. 2009. Epidermal homeostasis: A balancing act of stem cells in the skin. Nat Rev Mol Cell Biol 10: 207217.

Blumenthal GM, Dennis PA. 2008. PTEN hamartoma tumor syndromes. Eur J Hum Genet 16: 1289-1300.

Bouras T, Pal B, Vaillant F, Harburg G, Asselin-Labat ML, Oakes SR, Lindeman GJ, Visvader JE. 2008. Notch signaling 
regulates mammary stem cell function and luminal cellfate commitment. Cell Stem Cell 3: 429-441.

Chen X, Howard OM, Oppenheim JJ. 2007. Pertussis toxin by inducing IL-6 promotes the generation of IL-17-producing CD4 cells. J Immunol 178: 6123-6129.

Ciraolo E, Morello F, Hobbs RM, Wolf F, Marone R, Iezzi M, Lu X, Mengozzi G, Altruda F, Sorba G, et al. 2010. Essential role of the p110 3 subunit of phosphoinositide $3-\mathrm{OH}$ kinase in male fertility. Mol Biol Cell 21: 704-711.

Cully M, You H, Levine AJ, Mak TW. 2006. Beyond PTEN mutations: The PI3K pathway as an integrator of multiple inputs during tumorigenesis. Nat Rev Cancer 6: 184-192.

Dlugosz AA, Glick AB, Tennenbaum T, Weinberg WC, Yuspa SH. 1995. Isolation and utilization of epidermal keratinocytes for oncogene research. Methods Enzymol 254: 3-20.

Eng C. 2000. Will the real Cowden syndrome please stand up: Revised diagnostic criteria. I Med Genet 37: 828-830.

Fuchs E, Nowak JA. 2008. Building epithelial tissues from skin stem cells. Cold Spring Harb Symp Quant Biol 73: 333-350.

Graupera M, Guillermet-Guibert J, Foukas LC, Phng LK, Cain RJ, Salpekar A, Pearce W, Meek S, Millan J, Cutillas PR, et al. 2008. Angiogenesis selectively requires the p110 $\alpha$ isoform of PI3K to control endothelial cell migration. Nature 453: 662666.

Guillermet-Guibert J, Bjorklof K, Salpekar A, Gonella C, Ramadani F, Bilancio A, Meek S, Smith AJ, Okkenhaug K, Vanhaesebroeck B. 2008. The p110ß isoform of phosphoinositide 3-kinase signals downstream of G protein-coupled receptors and is functionally redundant with p110\%. Proc Natl Acad Sci 105: 8292-8297.

Gustafson S, Zbuk KM, Scacheri C, Eng C. 2007. Cowden syndrome. Semin Oncol 34: 428-434.

Hobert JA, Eng C. 2009. PTEN hamartoma tumor syndrome: An overview. Genet Med 11: 687-694.

Jamieson S, Flanagan JU, Kolekar S, Buchanan C, Kendall JD, Lee WJ, Rewcastle GW, Denny WA, Singh R, Dickson J, et al. 2011. A drug targeting only p110 $\alpha$ can block phosphoinositide 3-kinase signalling and tumour growth in certain cell types. Biochem I 438: 53-62.

Jia S, Liu Z, Zhang S, Liu P, Zhang L, Lee SH, Zhang J, Signoretti S, Loda M, Roberts TM, et al. 2008. Essential roles of PI(3)K$\mathrm{p} 110 \beta$ in cell growth, metabolism and tumorigenesis. Nature 454: 776-779.

Jia S, Roberts TM, Zhao JJ. 2009. Should individual PI3 kinase isoforms be targeted in cancer? Curr Opin Cell Biol 21: 199_ 208.

Jonkers J, Meuwissen R, van der Gulden $\mathrm{H}$, Peterse $\mathrm{H}$, van der Valk M, Berns A. 2001. Synergistic tumor suppressor activity of BRCA2 and p53 in a conditional mouse model for breast cancer. Nat Genet 29: 418-425.

Konecny GE, Pegram MD, Venkatesan N, Finn R, Yang G, Rahmeh M, Untch M, Rusnak DW, Spehar G, Mullin RJ, et al. 2006. Activity of the dual kinase inhibitor lapatinib (GW572016) against HER-2-overexpressing and trastuzumab-treated breast cancer cells. Cancer Res 66: 1630-1639.

Kroeze KL, Boink MA, Sampat-Sardjoepersad SC, Waaijman T, Scheper RJ, Gibbs S. 2012. Autocrine regulation of reepithelialization after wounding by chemokine receptors CCR1, CCR10, CXCR1, CXCR2, and CXCR3. I Invest Dermatol 132: 216-225.

Laury AR, Bongiovanni M, Tille JC, Kozakewich H, Nose V. 2011. Thyroid pathology in PTEN-hamartoma tumor syndrome: Characteristic findings of a distinct entity. Thyroid 21: 135-144.

Lesche R, Groszer M, Gao J, Wang Y, Messing A, Sun H, Liu X, Wu H. 2002. Cre/loxP-mediated inactivation of the murine Pten tumor suppressor gene. Genesis 32: 148-149.
Liaw D, Marsh DJ, Li J, Dahia PL, Wang SI, Zheng Z, Bose S, Call KM, Tsou HC, Peacocke M, et al. 1997. Germline mutations of the PTEN gene in Cowden disease, an inherited breast and thyroid cancer syndrome. Nat Genet 16: 64-67.

Liefer KM, Koster MI, Wang XJ, Yang A, McKeon F, Roop DR. 2000. Down-regulation of p63 is required for epidermal UVB-induced apoptosis. Cancer Res 60: 4016-4020.

Liu P, Cheng H, Roberts TM, Zhao JJ. 2009. Targeting the phosphoinositide 3-kinase pathway in cancer. Nat Rev Drug Discov 8: 627-644.

Maira SM, Pecchi S, Huang A, Burger M, Knapp M, Sterker D, Schnell C, Guthy D, Nagel T, Wiesmann M, et al. 2012. Identification and characterization of NVP-BKM120, an orally available pan-class I PI3-kinase inhibitor. Mol Cancer Ther 11: 317-328.

Nelen MR, Padberg GW, Peeters EA, Lin AY, van den Helm B, Frants RR, Coulon V, Goldstein AM, van Reen MM, Easton DF, et al. 1996. Localization of the gene for Cowden disease to chromosome 10q22-23. Nat Genet 13: 114-116.

Ni J, Liu Q, Xie S, Carlson C, Von T, Vogel K, Riddle S, Benes C, Eck M, Roberts T, et al. 2012. Functional characterization of an isoform-selective inhibitor of PI3K-p110 $\beta$ as a potential anticancer agent. Cancer Discovery 2: 425-433.

Pankow S, Bamberger C, Klippel A, Werner S. 2006. Regulation of epidermal homeostasis and repair by phosphoinositide 3-kinase. J Cell Sci 119: 4033-4046.

Salmena L, Carracedo A, Pandolfi PP. 2008. Tenets of PTEN tumor suppression. Cell 133: 403-414.

Sopasakis VR, Liu P, Suzuki R, Kondo T, Winnay J, Tran TT, Asano T, Smyth G, Sajan MP, Farese RV, et al. 2010. Specific roles of the p110 $\alpha$ isoform of phosphatidylinsositol 3-kinase in hepatic insulin signaling and metabolic regulation. Cell Metab 11: 220-230.

Squarize CH, Castilho RM, Gutkind JS. 2008. Chemoprevention and treatment of experimental Cowden's disease by mTOR inhibition with rapamycin. Cancer Res 68: 7066-7072.

Sulis ML, Parsons R. 2003. PTEN: From pathology to biology. Trends Cell Biol 13: 478-483.

Sun T, Aceto N, Meerbrey KL, Kessler JD, Zhou C, Migliaccio I, Nguyen DX, Pavlova NN, Botero M, Huang J, et al. 2011. Activation of multiple proto-oncogenic tyrosine kinases in breast cancer via loss of the PTPN12 phosphatase. Cell 144: 703-718.

Trotman LC, Alimonti A, Scaglioni PP, Koutcher JA, CordonCardo C, Pandolfi PP. 2006. Identification of a tumour suppressor network opposing nuclear Akt function. Nature 441: 523-527.

Utermark T, Rao T, Cheng H, Wang Q, Lee SH, Wang ZC, Iglehart JD, Roberts TM, Muller WJ, Zhao JJ. 2012. The p110 $\alpha$ and p110 $\beta$ isoforms of PI3K play divergent roles in mammary gland development and tumorigenesis. Genes Dev 26: 1573-1586.

Vanhaesebroeck B, Welham MJ, Kotani K, Stein R, Warne PH, Zvelebil MJ, Higashi K, Volinia S, Downward J, Waterfield MD. 1997. P1108, a novel phosphoinositide 3-kinase in leukocytes. Proc Natl Acad Sci 94: 4330-4335.

Vanhaesebroeck B, Guillermet-Guibert J, Graupera M, Bilanges B. 2010. The emerging mechanisms of isoform-specific PI3K signalling. Nat Rev Mol Cell Biol 11: 329-341.

Vivanco I, Sawyers CL. 2002. The phosphatidylinositol 3-kinase AKT pathway in human cancer. Nat Rev Cancer 2: 489-501.

Vogt PK, Gymnopoulos M, Hart JR. 2009. PI 3-kinase and cancer: Changing accents. Curr Opin Genet Dev 19: 12-17.

Yang A, Kaghad M, Wang Y, Gillett E, Fleming MD, Dotsch V, Andrews NC, Caput D, McKeon F. 1998. p63, a p53 homolog at 3q27-29, encodes multiple products with transactivating, 
Wang et al.

death-inducing, and dominant-negative activities. Mol Cell 2: 305-316.

Yi R, Poy MN, Stoffel M, Fuchs E. 2008. A skin microRNA promotes differentiation by repressing 'stemness.' Nature 452: 225-229.

Zhang L, Smith KM, Chong AL, Stempak D, Yeger H, Marrano P, Thorner PS, Irwin MS, Kaplan DR, Baruchel S. 2009. In vivo antitumor and antimetastatic activity of sunitinib in preclinical neuroblastoma mouse model. Neoplasia 11: 426435.

Zhao JJ, Liu Z, Wang L, Shin E, Loda MF, Roberts TM. 2005. The oncogenic properties of mutant $\mathrm{p} 110 \alpha$ and $\mathrm{p} 110 \beta$ phosphatidylinositol 3-kinases in human mammary epithelial cells. Proc Natl Acad Sci 102: 18443-18448.

Zhao JJ, Cheng H, Jia S, Wang L, Gjoerup OV, Mikami A, Roberts TM. 2006. The p110 $\alpha$ isoform of PI3K is essential for proper growth factor signaling and oncogenic transformation. Proc Natl Acad Sci 103: 16296-16300. 


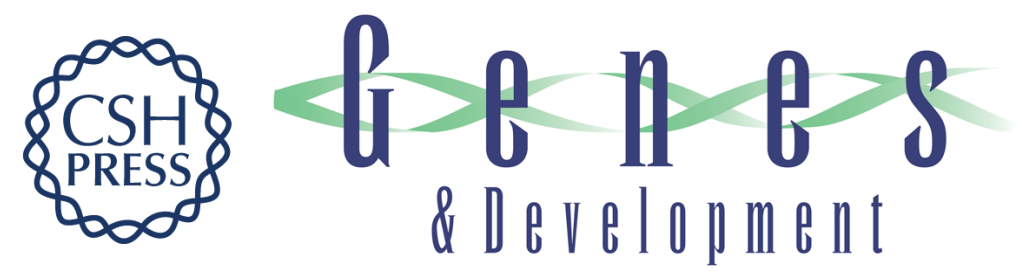

\section{Spatially distinct roles of class la PI3K isoforms in the development and maintenance of PTEN hamartoma tumor syndrome}

Qi Wang, Thanh Von, Roderick Bronson, et al.

Genes Dev. 2013, 27:

Access the most recent version at doi:10.1101/gad.216069.113

Supplemental http://genesdev.cshlp.org/content/suppl/2013/07/19/27.14.1568.DC1
Material

References This article cites 46 articles, 18 of which can be accessed free at:

http://genesdev.cshlp.org/content/27/14/1568.full.html\#ref-list-1

License

Email Alerting

Receive free email alerts when new articles cite this article - sign up in the box at the top

Service

right corner of the article or click here.

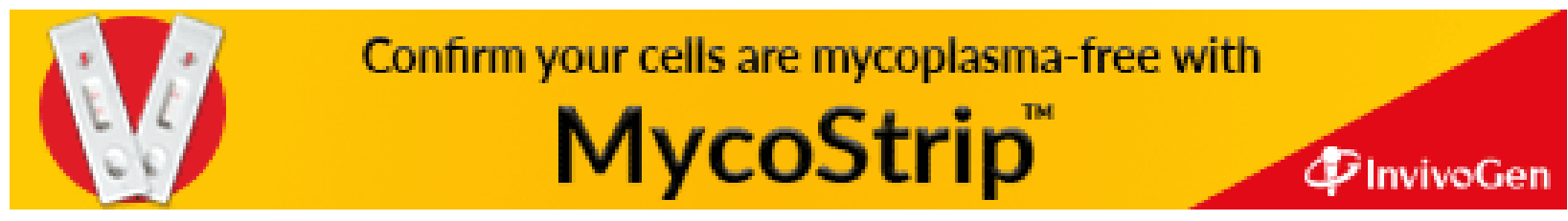

